\title{
Etavopivat, a Pyruvate Kinase Activator in Red Blood Cells, for the Treatment of Sickle Cell Disease
}

Patricia Schroeder, ${ }^{1}$ Keertik Fulzele, ${ }^{1}$ Sanjeev Forsyth, Maria D. Ribadeneira, Sylvie Guichard, Erik Wilker, C. Gary Marshall, Adam Drake, Rose Fessler, Diamantis G. Konstantinidis, Katie G. Seu, and Theodosia A. Kalfa

${ }^{1}$ Co first authors

Forma Therapeutics, Watertown, Massachusetts (P.S., K.F. ${ }^{2}$, S.F., M.D.R., S.G.); Tango

Therapeutics, Cambridge, Massachusetts (E.W.); Repare Therapeutics, Cambridge,

Massachusetts (C.G.M.); Ichnos Sciences, Epalinges Switzerland(A.D.); Cincinnati Children's

Hospital Medical Center, Cincinnati, Ohio (D.G.K, K.G.S., R.F., T.A.K.); and Department of

Pediatrics, College of Medicine, University of Cincinnati, Cincinnati, Ohio (T.A.K.)

${ }^{2}$ At the time of study conduct 
Running Title: Etavopivat for the treatment of sickle cell disease

Address correspondence to:

Theodosia A. Kalfa

Address: Cincinnati Children's Hospital Medical Center, Cincinnati, Ohio

Tel: 513-636-0989

Fax: 513-636-1330

E mail: Theodosia.Kalfa@cchmc.org

ORCID ID: https://orcid.org/0000-0002-0426-9686

Number of:

Text pages: 31

Figures: 7

References: 52

Supplementary files: 1 text file, 3 tables

Number of words in:

Abstract: $218 / 250$

Significance statement: 77/ 80

Introduction: 749/ 750

Discussion: 1344/ 1500 
NONSTANDARD ABBREVIATIONS: 2,3-DPG, 2,3-diphosphoglycerate; $\mathrm{AUC}_{0-24}$, area under the concentration time curve from time 0-24 hours after dosing; $\mathrm{C}_{\max }$; maximum plasma concentration; DMSO, dimethyl sulfoxide; $\mathrm{EC}_{50}$, half maximal effective concentration; EI, elongation index; HbS, hemoglobin S; HbSC, hemoglobin S and C; HbSS, homozygous hemoglobin S; HU, hydroxyurea; LC-MS/MS, liquid chromatography-tandem mass spectrometry; NHP, non-human primate; PD, pharmacodynamic; PK, pharmacokinetic; PKR, erythrocyte pyruvate kinase; $\mathrm{pO}_{2}$, partial pressure of oxygen; $\mathrm{P}_{50}$, the $\mathrm{pO}_{2}$ at which hemoglobin is $50 \%$ saturated with oxygen; PoS, point of sickling; RBC, red blood cell; SCD, sickle cell disease; TES, N-tris(hydroxymethyl)methyl-2-aminoethanesulfonic acid; VOC, vaso-occlusive crises.

SECTION: Drug Discovery and Translational Medicine 


\section{ABSTRACT}

Etavopivat is an investigational, oral, small molecule activator of erythrocyte pyruvate kinase (PKR) in development for the treatment of sickle cell disease (SCD) and other hemoglobinopathies. PKR activation is proposed to ameliorate the sickling of SCD red blood cells (RBC) through multiple mechanisms, including reduction of 2,3-diphosphoglycerate (2,3DPG), which consequently increases hemoglobin ( $\mathrm{Hb}$ )-oxygen affinity; increased binding of oxygen reduces $\mathrm{HbS}$ polymerization and sickling. In addition, PKR activation increases adenosine triphosphate (ATP) produced via glycolytic flux, which helps preserve membrane integrity and RBC deformability. We evaluated the pharmacodynamic response to etavopivat in non-human primates (NHP) and in healthy human subjects, and the effects in RBC from patients with SCD after ex vivo treatment with etavopivat. A single dose of etavopivat decreased 2,3DPG in NHP and healthy subjects. Hb-oxygen affinity was significantly increased in healthy subjects after 24 hours. Following daily dosing of etavopivat over 5 consecutive days in NHP, ATP was increased by $38 \%$ from baseline. Etavopivat increased $\mathrm{Hb}-$ oxygen affinity and reduced sickling in RBC collected from SCD patients with either HbSS or HbSC disease. Collectively, these results demonstrate the ability of etavopivat to decrease 2,3-DPG and increase ATP, resulting in increased $\mathrm{Hb}$-oxygen affinity and improved sickle $\mathrm{RBC}$ function. Etavopivat is currently being evaluated in clinical trials for the treatment of SCD.

ClinicalTrials.gov identifier: NCT03815695. 


\section{SIGNIFICANCE STATEMENT}

Etavopivat—a small molecule activator of the glycolytic enzyme erythrocyte pyruvate kinase decreased 2,3-diphosphoglycerate in red blood cells (RBC) from non-human primates and healthy subjects and significantly increased hemoglobin $(\mathrm{Hb})$-oxygen affinity in healthy subjects. Using ex vivo RBC from donors with sickle cell disease (SCD) (HbSS or HbSC genotype), etavopivat increased $\mathrm{Hb}$-oxygen affinity and reduced sickling under deoxygenation. Etavopivat shows promise as a treatment for $\mathrm{SCD}$, that potentially might reduce vaso-occlusion and improve anemia. 


\section{Introduction}

Sickle cell disease (SCD) is an autosomal recessive blood disorder caused by a single point mutation in the beta globin gene resulting in the expression of sickle hemoglobin (HbS). $\mathrm{HbS}$ tends to polymerize when deoxygenated in the low oxygen tension of capillaries, or even in arterioles. HbS polymerization alters red blood cell (RBC) morphology and negatively affects their function (Sundd et al., 2019). The two most common SCD genotypes are due to homozygosity for the beta-S mutation (p.Glu6Val) (HbSS), or compound heterozygosity for beta-S and beta-C (p.Glu6Lys) (HbSC) (da Guarda et al., 2020). The formation of cytoplasmic HbS polymers causes the RBC to adopt a rigid, sickle-like shape that is the defining characteristic of SCD (Kato et al., 2018). Sickled RBC display abnormal rheological properties, aggregate, and can lead to microcapillary blockage causing tissue hypoxia, which is experienced as a painful vaso-occlusive crisis (VOC). Repeated $\mathrm{HbS}$ polymerization and depolymerization with changing oxygen pressure, as well as oxidative damage, alters the RBC membrane, ultimately leading to a significantly shortened RBC lifespan, i.e., hemolysis (Sundd et al., 2019).

Despite increased reticulocyte production, this decreased RBC lifespan results in anemia. The physiologic metabolic response of RBC to anemia is to increase 2,3-DPG, thereby promoting release and offloading of oxygen from hemoglobin $(\mathrm{Hb})$ to tissues. (Charache et al., 1970). This shift to lower oxygen affinity promotes HbS deoxygenation and consequently, polymerization, leading to RBC sickling. Resulting changes in the RBC membrane such as expression of phosphatidyl serine on the cell surface lead to altered interaction with other blood cells and the endothelium. Together with the release of proinflammatory RBC contents upon hemolysis, these changes elicit an inflammatory response, including the activation of white blood cells and increased adhesion of sickle RBC and white blood cells to the endothelium (Telen, 
2007), resulting in the sudden, severe, and painful VOC episodes. VOC is the leading diagnosis associated with emergency department visits for patients with SCD (Yusuf et al., 2010); upwards of $40 \%$ of such emergency department visits can result in hospital admission (Lanzkron et al., 2010). VOCs also lead to secondary complications, such as acute chest syndrome, that cause end-organ damage and premature death in patients with SCD (Novelli and Gladwin, 2016).

Pyruvate kinase- $\mathrm{R}(\mathrm{PKR})$ is the RBC-expressed isoform of the key glycolytic enzyme pyruvate kinase. PKR catalyzes the last and rate-limiting step of glycolysis from phosphoenolpyruvate to pyruvate while generating adenosine triphosphate (ATP) from adenosine diphosphate. In patients with pyruvate kinase deficiency, decreased PKR activity results in anemia (Zanella et al., 2005), while activation of PKR improves RBC survival and $\mathrm{Hb}$ levels (Grace et al., 2019). We hypothesized that PKR activation above normal levels would alter several steps of the glycolytic pathway utilizing glucose to generate pyruvate. Increased PKR activity would be expected to decrease production of 2,3-DPG and increase production of ATP within RBC (Koralkova et al., 2014; Bianchi et al., 2019). PKR is therefore a logical target to activate for treatment of SCD as a decrease in 2,3-DPG levels would increase the affinity of $\mathrm{Hb}$ for oxygen, lowering the potential for $\mathrm{HbS}$ polymerization and $\mathrm{RBC}$ sickling.

Furthermore, an increase in ATP synthesis can enhance overall RBC function and health. Reduced ATP within RBC adversely affects ion homeostasis contributing to cell dehydration (Ortiz et al., 1990; Gallagher, 2017), membrane damage (de Jong et al., 2001; Soupene and Kuypers, 2006; Weiss et al., 2012), and impaired RBC deformability (Clark et al. 1980), all of which contribute to the pathophysiological features of SCD. By attenuating these adverse effects, an increase in ATP synthesis via PKR activation within sickle RBC would potentially have the 
dual beneficial effect of addressing the chronic anemia associated with SCD and reducing the incidence of VOC.

Here, we describe the cellular effects of etavopivat (FT-4202), a potent, selective, orally bioavailable PKR activator (Ericsson et al., 2020). Using oral dosing studies in non-human primates (NHP) and healthy subjects, we demonstrate that etavopivat decreases 2,3-DPG and increases ATP in RBC. We also present the results of a series of pharmacodynamic (PD) assays after in vivo treatment of healthy RBCs and ex vivo treatment of sickle RBCs with etavopivat supporting the relevance of these biomarkers when evaluating response to this investigational agent. This work demonstrates the translational value of measurements adopted in preclinical and early clinical development, which are indicative of RBC health. We present target engagement data (single 700-mg dose) from the first-in-human clinical trial that provides a platform of evidence supporting further clinical development of etavopivat for the treatment of SCD.

\section{Materials and Methods}

\section{In Vivo Studies}

Procedures in Cynomolgus Monkeys. The pharmacokinetics (PK) and PD of etavopivat were assessed in male cynomolgus monkeys. The decision to use male cynomolgus monkeys was based on availability only. There were no PK/PD gender differences observed during preclinical multiple-dose safety studies. Animals (AlphaGenesis, Inc., SC, USA) were of Chinese origin, in good health (non-naïve), and housed, cared for, and acclimated to study procedures in compliance with the testing facility Institutional Animal Care and Use Committee (IACUC) Guidelines and Standard Operating Procedure (Biomere, MA, USA). NHP experiments were 
approved by the IACUC at Biomere, MA and conducted according to the National Institutes of Health Guide for the Care and Use of Laboratory Animals (National Research Council, 2011). A spray-dried dispersion of etavopivat was delivered in a vehicle solution containing $0.5 \%$ hydroxypropyl methylcellulose and administered to monkeys by oral gavage. In a singledose experiment, monkeys $(n=4)$ received etavopivat at a dose of $50 \mathrm{mg} / \mathrm{kg}$. In a multiple-dose experiment, animals received a dose of $0.5 \%$ hydroxypropyl methylcellulose (control; $n=3$ ), or a dose of etavopivat at 3,8 , or $22 \mathrm{mg} / \mathrm{kg}$ ( $n=4$ per group) once daily (QD) on 5 consecutive days. The dose volume for all groups was $5 \mathrm{ml} / \mathrm{kg}$. For the single-dose experiment, whole blood samples $(\sim 0.5 \mathrm{ml})$ for determination of plasma concentrations of etavopivat and whole blood 2,3DPG and ATP were collected pre-dose, 30 minutes, 1-, 2-, 4-, 6-, 8-, 12-, and 24-hours postdose. For the multiple-dose experiment, blood samples were collected 1-, 6-, 12-, and 24-hours post-dose on day $1(\sim 0.5 \mathrm{ml})$, and pre-dose, 30 minutes, 1-, 2-, 4-, 6-, 8-, 12-, and 24-hours postdose on day $5(\sim 0.8 \mathrm{ml})$.

Single-Dose Plasma PK and PD of Etavopivat in Healthy Subjects. Key aspects of the firstin-human study of etavopivat are summarized below. The study was performed in accordance with the Declaration of Helsinki and Good Clinical Practice guidelines and was approved by the relevant institutional review board. Subjects were healthy volunteers aged 18 to 60 years inclusive and provided written informed consent.

The single-ascending dose portion of the study was a phase 1, single-center, randomized, placebo-controlled, double-blind dose escalation study to assess the safety, tolerability, PK, and PD following a single oral dose of etavopivat in healthy subjects (ClinicalTrials.gov identifier: NCT03815695). Placebo and etavopivat were administered orally to subjects after overnight 
fasting. Successively escalated dose levels of etavopivat at 200, 400, 700, and $1000 \mathrm{mg}$ were evaluated. For each sequential dose cohort, eight subjects were randomly assigned 2:6 to receive a single oral dose of placebo or etavopivat, respectively. Blood samples were collected pre- and post-etavopivat dosing at serial timepoints for PK/PD assessment. Etavopivat plasma concentrations were measured using a validated liquid chromatography-tandem mass spectrometry (LC-MS/MS) method. The lower and upper limits of quantitation were 1 and 1000 ng/ml, respectively. 2,3-DPG and ATP in whole blood were measured using a separate LCMS/MS method as described below. Hb-oxygen affinity and values for the dissolved oxygen pressure $\left(\mathrm{pO}_{2}\right)$ at which $\mathrm{Hb}$ is $50 \%$ saturated with oxygen $\left(\mathrm{P}_{50}\right)$ were measured in whole blood by generating oxygen equilibrium curves as described below. Non-compartmental PK analysis of etavopivat was conducted using Phoenix WinNonlin ${ }^{\circledR}$ (Certara, Princeton, NJ).

\section{In vitro Studies}

Activation of PKR in Human Red Blood Cells. The activation of wild type PKR by etavopivat in mature human RBC ex vivo was evaluated in purified RBC purchased from Research Blood Components (Watertown, MA). Varying concentrations of etavopivat stock solutions $(2.5 \mu 1)$ were added to $22.5 \mu \mathrm{l}$ of washed human $\mathrm{RBC}(0.75$ million $)$ in the range of $2 \mathrm{nM}$ to $30 \mu \mathrm{M}$, in Roswell Park Memorial Institute Medium (Corning; Corning, NY), and incubated for $3 \mathrm{~h}$ at $37^{\circ} \mathrm{C}$. Cells were spun at $1500 \mathrm{rpm}$ for $5 \mathrm{~min}$ and the supernatant was removed. Cells were washed twice using $200 \mu \mathrm{l}$ of PBS and a 5 min $1500 \mathrm{rpm}$ spin cycle. After the second wash, the RBC pellet was lysed for 30 min in $200 \mu$ l of assay buffer. Following a 5 min spin at $1500 \mathrm{rpm}$, lysate was assayed using a Biovision (Milpitas, CA) Pyruvate Kinase Assay (Catalog \# K709100). 
Whole Blood from Patients with SCD. Whole blood samples from female and male patients homozygous for $\mathrm{HbS}$ (HbSS), or compound heterozygous for $\mathrm{HbS}$ and $\mathrm{HbC}(\mathrm{HbSC})$, were collected in vacutainers with $\mathrm{K}_{2}$-EDTA as an anti-coagulant, at Cincinnati Children's Hospital, with informed consent and in accordance with an Independent Review Board-approved protocol. Whole blood samples $(250 \mu \mathrm{l})$ from normal control donors (HbAA) and patients with SCD were washed twice with $1 \mathrm{ml}$ Hanks' Balanced Salt Solution (Thermo Fisher Scientific) containing 10 mM HEPES, $10 \mathrm{mM} \mathrm{MgCl}_{2}$, and $5.5 \mathrm{mM}$ glucose at $\mathrm{pH} 7.4$ (Buffer 1) and centrifuged at $400 \times \mathrm{g}$ for 5 minutes. Supernatant was removed by aspiration. The RBC pellet was resuspended in $1 \mathrm{ml}$ of Buffer 1 and centrifuged for 5 minutes at $800 \times g$ to pack the cells. Supernatant was aspirated and packed RBC were resuspended to $20 \%$ (v/v) (20\% hematocrit) with Buffer 1 and incubated for 4 hours at $37^{\circ} \mathrm{C}$ with $20 \mu \mathrm{M}$ etavopivat in dimethyl sulfoxide (DMSO) or equivalent volume of vehicle control (DMSO only) on a VWR Incubating Orbital Shaker 3500 (VWR International, Radnor, PA) at $250 \mathrm{rpm}$. The concentration of $20 \mu \mathrm{M}$ etavopivat was selected based on preliminary work showing that this concentration consistently decreased p50 in RBC incubated in vitro with etavopivat for $3 \mathrm{~h}$ at $37^{\circ} \mathrm{C}$. $\mathrm{Hb}$-oxygen dissociation curves and oxygenscans were performed as described below, to determine $\mathrm{P}_{50}$ and point of sickling $(\mathrm{PoS})$, respectively.

Simultaneous Measurement of 2,3-DPG and ATP in Whole Blood. 2,3-DPG and ATP were measured in $\mathrm{K}_{2}$-EDTA-anticoagulated whole blood samples of monkeys or humans using LCMS/MS. The analysis was performed using an API-5500 triple-quadrupole mass spectrometer (AB Sciex, Redwood City, CA) coupled with an Agilent 1200 series high-performance liquid chromatography system (Agilent 1260 Infinity Bin Pump and G1379B Degasser, Agilent, Santa 
Clara, CA) and a Thermo Scientific CTC-PAL autosampler (Thermo Fisher Scientific, Waltham, MA). Analyst ${ }^{\circledR}$ 1.6.2 (Sciex) and Aria MX software (Thermo Fisher Scientific) were used for instrument control, data acquisition, and data analysis. Calibration standards (25.0-1500 $\mu \mathrm{g} / \mathrm{ml})$, quality controls, and study samples were thawed on wet ice and vortex-mixed for approximately 2 minutes before being pipetted. Because ATP and 2,3-DPG are endogenous molecules present in whole blood at high levels, the low, middle, and high quality control calibration standards were prepared in deionized water (surrogate matrix). Whole blood samples $(15 \mu \mathrm{l})$ were spiked with stable isotope-labeled internal standard $\left({ }^{13} \mathrm{C}_{10},{ }^{15} \mathrm{~N}_{5}-\mathrm{ATP}\right.$, and $\left.\mathrm{D}_{3}-2,3-\mathrm{DPG}\right)$, processed by protein precipitation extraction, and analyzed using ZIC ${ }^{\circledR}$-pHILIC separation with Turbo Ion Spray ${ }^{\circledR}$ MS/MS detection. Negative (M-H) ${ }^{-}$ions for ATP and 2,3-DPG and their respective internal standards, ${ }^{13} \mathrm{C}_{10},{ }^{15} \mathrm{~N}_{5}-\mathrm{ATP}$, and $\mathrm{D}_{3}-2,3-\mathrm{DPG}$, were monitored in multiple reaction monitoring mode. Analyte to internal standard peak area ratios for the standards were used to create a quadratic calibration curve using $1 / \mathrm{x}^{2}$ weighted least-squares regression analysis. For both analytes, the overall accuracy of the method was within $\pm 10.5 \%$ ( $\%$ relative error), and the intra- and inter-assay precision percent coefficient of variation $(\% \mathrm{CV})$ were less than $7 \%$.

Hb-Oxygen Dissociation Curve and $\mathbf{P}_{50}$ Assessment. The $\mathrm{Hb}-$ oxygen equilibrium curves were collected using a TCS HEMOX Analyzer (Guarnone et al., 1995) (TCS Scientific Corp., New Hope, PA) providing the level of oxygenated $\mathrm{Hb}$ (expressed as percentage) as a function of $\mathrm{pO}_{2}$ (mmHg). Whole blood samples from healthy subjects were collected in $\mathrm{K}_{2}$-EDTA tubes 24 hours after etavopivat treatment. For ex vivo treatment, RBC from patients with SCD were prepared as described above. The whole blood samples or the ex vivo etavopivat-treated RBC were diluted 
50-fold into pre-warmed $\left(37^{\circ} \mathrm{C}\right)$ TES sodium salt buffer (Sigma Aldrich) containing 20 - $\mu$ l bovine serum albumin-20 additive $\mathrm{A}$ and $10-\mu \mathrm{l}$ anti-foaming agent- 25 per $5 \mathrm{ml}$ of buffer.

Samples were oxygenated using compressed air. Measurement using the HEMOX Analyzer (TCS Scientific) started at an oxygen pressure of $145 \mathrm{mmHg}$ following replacement of air with nitrogen and was stopped automatically at an oxygen pressure of $1.9 \mathrm{mmHg}$. Results were analyzed using the HEMOX Analyzer Software; non-linear regression analysis was performed to obtain the $\mathrm{P}_{50}$ value.

Oxygenscan and PoS Calculations. Oxygen gradient ektacytometry (oxygenscan) using a Laser Optical Rotational Red Cell Analyzer (Lorrca ${ }^{\circledR}$ ) (RR Mechatronics, Zwaag, The Netherlands) (Rab et al., 2019; Sadaf et al., 2021) was performed to evaluate changes in the deformability of RBC with or without previous etavopivat treatment as a function of oxygen pressure under steady shear stress. $200 \times 10^{6} \mathrm{RBC}$ from patients with SCD treated ex vivo with DMSO or etavopivat, as detailed above, were suspended in $5 \mathrm{ml}$ of Oxy Iso (osmolality 282-286 $\mathrm{mOsm} / \mathrm{kg}, \mathrm{pH}$ 7.35-7.45) at room temperature. The RBC suspension was injected into a rotating wall cylinder maintained at $37^{\circ} \mathrm{C}$ with a fixed shear stress of 30 pascal. Deoxygenation and reoxygenation of the RBC suspension was achieved by gradual entry of nitrogen gas and ambient air, respectively. One oxygenscan consisted of approximately 80 measurements of the elongation index (EI) during one round of deoxygenation (1300 seconds) and was followed by reoxygenation (280 seconds). Oxygen saturation in the RBC suspension was calculated every 20 seconds based on quenching of the signal using a luminophore oxygen-sensor. Ambient air $\mathrm{pO}_{2}$ in the cup of the device started at approximately $150 \mathrm{mmHg}$ and was gradually lowered to below $20 \mathrm{mmHg}$ of oxygen. The $\mathrm{PoS}$ in oxygenscan is calculated as the $\mathrm{pO}_{2}(\mathrm{mmHg})$ at which the EI 
falls below 5\% of the maximum EI (EImax) during deoxygenation and indicates the oxygen pressure at which the polymerization of $\mathrm{HbS}$ starts to show effects on RBC deformability.

\section{Statistics}

Statistical analysis was performed using Prism, Version 8.4 (GraphPad Software, San Diego, CA). Paired T-test or Wilcoxon tests were used as appropriate. A $P$ value less than 0.05 was considered statistically significant for all tests. All preclinical experiments should be considered exploratory. The sample size for the phase 1 study was considered adequate to evaluate the safety, tolerability, and PK/PD of etavopivat; no formal power calculations were performed.

\section{Results}

\section{Etavopivat activates PKR in Healthy Human RBC in vitro}

The activation of wild type PKR by etavopivat in mature human RBC in vivo was evaluated in purified RBC. Wild type PKR was activated in a concentration-dependent manner. The calculated mean maximum activation was $89 \%$ and the half maximal effective concentration (EC 50$)$ was $113 \mathrm{nM}$.

\section{Etavopivat Modulates 2,3-DPG and ATP in Cynomolgus Monkeys}

Following the administration of a single $50-\mathrm{mg} / \mathrm{kg}$ dose of etavopivat in NHP, the etavopivat plasma concentration reached its maximal value $\left(\mathrm{C}_{\max }\right)$ between 1- and 2-hours post-dose, and 2,3-DPG declined to $47 \%$ of the baseline concentration between 12- and 24-hours post-dose $(P=0.04)$ (Fig. 1), which approaches the theoretical maximum calculated by 2,3-DPG PK/PD 
modeling (Text S1). Following five consecutive daily doses of etavopivat at lower dose levels $(3,8$, and $22 \mathrm{mg} / \mathrm{kg})$, the maximum mean decrease in the concentration of 2,3-DPG occurred 12 hours post-dose on day 1 (Fig. 2A), 12 hours post-etavopivat $\mathrm{C}_{\max }($ Fig. 2B). The mean concentrations of 2,3-DPG observed on day 5 were comparable to those observed on day 1 (Fig. 2A), with mean decreases from baseline of $19 \%(P=0.09), 25 \%(P=0.02)$, and $36 \%(P=0.002)$, respectively, $12 \mathrm{~h}$ after the last dose on day 5.

Due to the temporal delay between etavopivat plasma concentration and 2,3-DPG modulation, direct plots between etavopivat PK and 2,3-DPG response are not meaningful. An indirect PK/PD model, previously applied to describe 2,3-DPG PK/PD relationships (Kha et al., 2015) and described in the supplementary section (Text S1), was used to quantitate the exposure-response relationship. This analysis estimates the maximal 2,3-DPG decrease from baseline in NHP with etavopivat is approximately 50\%, where the plasma concentration to achieve half of this maximum effect at PK/PD steady state $\left(\mathrm{RC}_{50}\right)$, a $25 \%$ decrease in 2,3-DPG, is $\sim 18 \mathrm{ng} / \mathrm{mL}(34 \mathrm{nM})$ from equation 4. Primary PK/PD parameters in NHP are summarized in

\section{Table S1.}

Following a single $50 \mathrm{mg} / \mathrm{kg}$ dose, ATP was not significantly elevated from baseline up to $24 \mathrm{~h}$ post dose. To understand the temporal behavior of ATP elevation upon etavopivat administration, ATP was measured in whole blood from NHP dosed with 3, 8, or $22 \mathrm{mg} / \mathrm{kg}$ QD for 5 consecutive days. Concentrations of ATP were not significantly altered at any dose on day 1 (Fig. 2C); however, by day 5, ATP concentrations were elevated at the 8 and $22 \mathrm{mg} / \mathrm{kg}$ doses, with day average increases of $18 \%(P=0.0004)$ and $38 \%(P=0.004)$, respectively, relative to average levels on day 1 . As the dynamics of ATP formation and clearance were not adequately captured, this precluded a quantitative assessment of in vivo $\mathrm{EC}_{50}$ for ATP. Etavopivat $\mathrm{C}_{\max }$ and 
area under the concentration time curve from time $0-24 \mathrm{~h}$ after dosing $\left(\mathrm{AUC}_{0-24}\right)$ following single and repeated escalating doses in NHP are presented in Table S2. Day 5 percent changes of 2,3-DPG and ATP, along with exposure (Day $5 \mathrm{AUC}_{0-24}$ ) are summarized in Fig. 3.

\section{Ex vivo Etavopivat Treatment of RBC from Patients with SCD Improved Hb-Oxygen}

\section{Affinity and Reduced PoS}

The ability of etavopivat to increase $\mathrm{Hb}-$ oxygen affinity in healthy subjects treated with a single dose (Fig. 4A) is indicative of the potential to mitigate the rate and extent of RBC sickling in patients with SCD. We tested this possibility ex vivo, using whole blood from donors with either HbSS or HbSC. The p50 in the patients' specimens before the in vitro incubation with vehicle-control or etavopivat was in the range of 28-34 mmHg. Despite optimization of the in vitro incubation media, especially of the buffer composition to maintain as possible stable $\mathrm{CO}_{2}$ and $\mathrm{pH}$, the $\mathrm{p} 50$ values of the sickle red cells incubated under control conditions were relatively lower than baseline as shown in Fig. 4B and C. Nevertheless, etavopivat-incubated RBC under the same conditions as vehicle-control significantly reduced p50. The mean (standard deviation [S.D.]) decrease in $\mathrm{P}_{50}$ following treatment with etavopivat versus vehicle was $1.27 \pm 0.76$ mmHg and $1.47 \pm 0.63 \mathrm{mmHg}$ in $\mathrm{HbSS}$ and HbSC donors, respectively (Table S3). In the HbSS group, $\mathrm{P}_{50}$ (mean \pm S.D.) was reduced to $24.8 \pm 1.82 \mathrm{mmHg}$ after 4-hour incubation with etavopivat compared with $26.1 \pm 1.99 \mathrm{mmHg}$ in the vehicle-treated group $(P=0.0002)$ (Fig. 4B). For the HbSC group, $\mathrm{P}_{50}$ was reduced to $24.8 \pm 1.58 \mathrm{mmHg}$ after incubation with etavopivat compared with $26.3 \pm 1.24 \mathrm{mmHg}$ in the vehicle-treated group $(P=0.0313)$ (Fig. 4C). Etavopivat treatment induced a leftward shift of the $\mathrm{Hb}$-oxygen dissociation curve in $\mathrm{RBC}$ from donors with 
either HbSS or HbSC (Fig. 4D, E) suggesting an improved oxygen-carrying capacity of $\mathrm{Hb}$ under conditions of decreased oxygen pressure.

We tested the deformability of $\mathrm{RBC}$ across a $\mathrm{pO}_{2}$ range, from 150 to $<20 \mathrm{mmHg}$, using oxygen gradient ektacytometry. $\mathrm{PoS}$ was calculated as the $\mathrm{pO}_{2}$ at which $\mathrm{RBC}$ maximal deformability (EImax) decreased by 5\%. The mean (S.D.) decrease in PoS following incubation with etavopivat for 4 hours versus vehicle was $3.53 \pm 4.29 \mathrm{mmHg}$ and $3.91 \pm 2.40 \mathrm{mmHg}$ in HbSS and HbSC donors, respectively. Ex vivo incubation of RBC from patients with HbSS with etavopivat decreased the PoS (mean \pm S.D.) to $28.3 \pm 8.09 \mathrm{mmHg}$ compared with $31.9 \pm 7.93$ $\mathrm{mmHg}$ in the paired samples treated with vehicle control $(P=0.0244)$ (Fig. 5A, C). PoS was also decreased in etavopivat-treated $(19.3 \pm 5.11 \mathrm{mmHg})$ versus vehicle-treated $(23.2 \pm 5.61 \mathrm{mmHg})$ RBC from donors with $\operatorname{HbSC}(P=0.0313)$ (Fig. 5B, D).

\section{Human PK of Etavopivat}

Following a single oral dose of $700 \mathrm{mg}$ in healthy subjects (one female, five male), etavopivat was rapidly absorbed and median time to maximum concentration was approximately 0.5 hours. After reaching peak concentrations, mean concentrations of etavopivat declined in a multi-exponential manner (Fig. 6). The estimated elimination $t_{1 / 2}$ was approximately 13 hours. Area under the concentration time curve from time 0 extrapolated to infinity (geometric mean [\%CV]) was $6995(29.4) \mathrm{ng} \cdot \mathrm{h} / \mathrm{ml}$. Moderate inter-subject variability in plasma etavopivat concentrations was observed. 


\section{Etavopivat Decreases 2,3-DPG and Increases Hb-Oxygen Affinity in Healthy Subjects}

The PD profile following a single 700-mg dose of etavopivat in healthy subjects was comparable with a single 50-mg/kg dose in NHP. The maximum inhibition of 2,3-DPG was observed 24-hours post-dose, lagging behind the etavopivat $\mathrm{C}_{\max }$, which was observed approximately 0.5 hours post-dose. In healthy subjects, concentrations of 2,3-DPG were collected for 7 days following a single $700 \mathrm{mg}$ dose; maximal reductions of 2,3-DPG (mean 49\%; $\mathrm{p}=0.0313$ ) were durable, lasted 48-hours post-dose, and returned to baseline by day 7 (Fig. 6). Changes in whole blood concentrations of ATP following a single dose were not significant. Following a single 700-mg dose in healthy subjects, etavopivat was also shown to increase $\mathrm{Hb}-$ oxygen affinity (or decrease $\mathrm{P}_{50}$ ) by $4.85 \mathrm{mmHg}$ at 24 hours, when the greatest decrease in 2,3DPG was observed (Table S3). 2,3-DPG and $\mathrm{P}_{50}$ were correlated positively, providing a PKR activation-mediated PD response to etavopivat that increased $\mathrm{Hb}-$ oxygen affinity (Fig. 7).

\section{Discussion}

Advancements in disease-modifying therapies are urgently needed for patients with SCD. Through methodical medicinal chemistry efforts, we have identified etavopivat, a potent, selective, orally bioavailable, and novel PKR activator. Here, we present data from preclinical NHP and early-stage clinical human studies to show that etavopivat decreased 2,3-DPG, and increased ATP in NHP following daily dosing. In RBC from donors with SCD, etavopivat increased $\mathrm{Hb}-$ oxygen affinity of RBC and delayed sickling upon deoxygenation. Decreasing the level of deoxygenation that RBCs can tolerate, before sickling, may reduce the incidence of VOC in patients with SCD. 
Targeting PKR activation to reduce the concentration of 2,3-DPG is based on the ratelimiting role that PKR plays in regulating glycolysis in RBC. A decrease in 2,3-DPG with PKR activation has been demonstrated in preclinical studies, in healthy subjects, and in patients with PKR deficiency after treatment (Chubukov et al., 2016; Kung et al., 2017; Yang et al., 2019). Decreases in 2,3-DPG in both NHP and humans were delayed relative to peak plasma concentrations of etavopivat. More specifically, in NHP, maximum decreases in whole blood 2,3-DPG were observed between 12- and 24-hours post-dose, sometime after the mean $\mathrm{C}_{\max }$ was achieved, typically 1-hour post-dose. A comparable observation was made following a single 700-mg dose in healthy subjects. Notably, the maximal decrease in 2,3-DPG in healthy subjects treated with a single $700 \mathrm{mg}$ dose of etavopivat was durable for 48 hours before slowly returning to baseline by day 7 . Following a single dose, maximum decreases in 2,3-DPG in NHP dosed with $50 \mathrm{mg} / \mathrm{kg}$ and healthy human subjects treated with $700 \mathrm{mg}$ was $47 \%$ and $49 \%$, respectively, consistent with comparable unbound exposure at those dose levels (2342 and $2099 \mathrm{ng} / \mathrm{ml} * \mathrm{~h}$ for NHP and humans, respectively). Mitigating 2,3-DPG has been proposed as a means to reduce HbS polymerization in patients with SCD (Eaton and Bunn, 2017). Basal concentrations of 2,3DPG are higher in patients with SCD compared with healthy controls (Charache et al., 1970; Castro, 1980; Ould Amar et al., 1996), and depletion of 2,3-DPG has been shown to reduce the tendency for RBC sickling in patients with SCD (Poillon et al., 1995).

2,3-DPG strongly influences the binding of oxygen to $\mathrm{Hb}$; by binding within the central cavity of the $\mathrm{Hb}$ tetramer, 2,3-DPG causes allosteric changes, and reduces the molecule's affinity to oxygen (MacDonald, 1977). Increased $\mathrm{Hb}$-oxygen affinity (decreased $\mathrm{P}_{50}$ ) with a mean delta $\mathrm{P}_{50}$ of $4.85 \mathrm{mmHg}$ was observed in healthy subjects following the administration of a single 700- 
mg dose of etavopivat. $\mathrm{P}_{50}$ and 2,3-DPG in blood were strongly correlated before and 24 hours following a single dose of etavopivat. The 2,3-DPG-mediated effect provides a PD-based rationale for the increased $\mathrm{Hb}-$ oxygen affinity after treatment with etavopivat. Furthermore, ex vivo experiments using RBC from donors with $\mathrm{HbSS}$ or HbSC showed decreases in $\mathrm{P}_{50}$, indicating increased $\mathrm{Hb}$-oxygen affinity in the presence of etavopivat. Since higher concentrations of 2,3-DPG are associated with increases in deoxy-Hb, therapeutic approaches that increase $\mathrm{Hb}$-oxygen affinity and consequently reduce deoxygenation of $\mathrm{HbS}$, are expected to decrease $\mathrm{HbS}$ polymerization, reduce sickling, and attenuate the clinical consequences of SCD.

In addition to the reduction in 2,3-DPG and associated improvement in $\mathrm{Hb}$-oxygen affinity, the increased glycolytic flux induced by PKR activation is expected to increase RBC function and health by increasing ATP and reducing oxidative stress. Although no meaningful elevation in ATP was observed following a single dose in monkeys or healthy subjects, ATP concentrations were elevated by as much as $38 \%(P=0.004)$ relative to day 1 in NHP following 5 consecutive days of QD doses of etavopivat. In a recent study in Berkeley sickle cell anemia mice, ATP levels were increased $(P<0.01)$ following two weeks of treatment with etavopivat, corresponding with etavopivat plasma levels of $7702 \pm 796 \mathrm{ng} / \mathrm{mL}$ (Shrestha et al., 2021). ATP plays an essential role in maintenance of RBC membrane-cytoskeletal integrity (Betz et al., 2009), membrane repair via activation of flippase to re-internalize phosphatidyl serine to the inner leaflet of the RBC membrane (Soupene and Kuypers, 2006; Weiss et al., 2012), cell hydration (Gallagher, 2017), maintenance of ionic $\left(\mathrm{Mg}^{2+}\right.$ and $\mathrm{Ca}^{2+}$ ) gradients (Ortiz et al. 1990; Raftos et al., 1999; Rivera et al., 2005), RBC deformability (Weed et al., 1969; McMahon, 2019), and protection from oxidative damage (Banerjee and Kuypers, 2004). Therefore, 
increasing ATP concentrations is likely to have broad beneficial effects for patients with SCD. Moreover, in the current study, ex vivo treatment with etavopivat significantly improved the PoS in the RBC from donors with the HbSS genotype, likely due to a reduction in 2,3-DPG. These dual effects of decreased 2,3-DPG and increased ATP suggest that etavopivat has the potential to reduce RBC sickling, hemolysis, anemia, and consequently, VOC.

Pharmacologic interventions in clinical practice or development for the treatment of SCD include approaches to increase fetal $\mathrm{Hb}$ or $\mathrm{Hb}$ oxygenation in order to decrease $\mathrm{Hb}$ polymerization, and to decrease vascular adhesion. The current standard of care for most patients with SCD is hydroxyurea (HU), which reduces sickling by increasing fetal $\mathrm{Hb}$ in $\mathrm{RBC}$ and reduces painful episodes of VOC by $\sim 50 \%$; however, the effectiveness of HU can be confounded by poor patient compliance and discontinuation rates can be high (Brandow and Panepinto, 2010; Agrawal et al., 2014; Shah et al., 2019). In addition, while HU is broadly efficacious, response to treatment can be variable, and a proportion of patients (10-20\%) are non-responsive (Steinberg et al., 1997; Ma et al., 2007; Steinberg, 2008). Furthermore, HU is a myelosuppressive agent that may cause neutropenia and thrombocytopenia and thus requires routine blood monitoring for side effects (Agrawal et al., 2014). While HU has been used to treat SCD for over 30 years, there remains a need for improved disease management, more pharmacological options, and the possibility of combination therapies to target different aspects of SCD pathology. Crizanlizumab was recently approved to reduce the frequency of VOC in adults and pediatric patients aged 16 years and older with SCD. However, no improvement in hemolysis, anemia, or markers of inflammation have been observed (Ataga et al., 2017; Blair, 2020a). These data suggest that although targeting endothelial adhesion may decrease the incidence and severity of VOC, these agents are unlikely to address the anemia or chronic tissue damage associated with SCD. Drugs 
that increase $\mathrm{Hb}$-oxygen affinity, such as the recently approved agent voxelotor, directly interfere with $\mathrm{HbS}$ polymerization by maintaining a higher proportion of $\mathrm{Hb}$ in oxygenated state (Vichinsky et al., 2019; Blair, 2020b). Although the clinical safety profile for voxelotor to date has been positive, there is a recognized risk that excessive oxygen affinity could cause hypoxia by preventing release of oxygen into tissues, for which routine neurovascular monitoring has been recommended (Hebbel and Hedlund, 2017). Activation of PKR follows a physiological pathway that increases $\mathrm{Hb}$-oxygen affinity by decreasing 2,3-DPG and is likely to counteract the pathophysiology of SCD while enabling oxygen release in hypoxic tissues. As a result of the combination of decreased 2,3-DPG and increased ATP, it is proposed that targeting PKR activation may have a broad and significant impact on SCD, both in HbSS and HbSC, by improving the membrane integrity of RBC.

In conclusion, by virtue of its ability to promote activity in the glycolytic pathway, etavopivat is hypothesized to have unique, beneficial, disease-modifying effects on SCD. As the enzyme that catalyzes the last step of glycolysis, PKR underpins reactions that directly impact the metabolic health and primary functions of RBC. Etavopivat has two key effects: first, it decreases 2,3-DPG, which can reduce $\mathrm{HbS}$ polymerization and potentially attenuate clinical sequela of vaso-occlusion in SCD, and second, it increases ATP, which provides metabolic resources to support membrane integrity and protect against the loss of RBC deformability, and potentially to mitigate hemolysis in patients with SCD. The PD response to etavopivat in relation to PKR was demonstrated pre-clinically and confirmed in the first-in-human trial, providing valuable evidence of target modulation, which supports the rationale for subsequent clinical trials. Furthermore, the preliminary safety profile of etavopivat supports its advancement to 
additional clinical trials to determine the risk/benefit profile of PKR activation in SCD. Clinical trials of etavopivat in patients with SCD are currently in progress.

\section{Acknowledgments}

The authors would like to thank Dr Frans Kuypers for helpful discussions and Dr Eric Wu for his contribution to statistical analyses. Medical writing assistance was provided by Sue Reinwald, PhD, and Katy Beck, PhD, of Engage Scientific Solutions, Horsham, UK, and was funded by Forma Therapeutics, Inc.

\section{Authorship Contributions}

Participated in research design: Schroeder, Fulzele, Kalfa, Seu, Konstantinidis, Drake, Wilker, Marshall, Guichard, Forsyth, Ribadeneira

Conducted experiments: Fessler, Konstantinidis, Seu, Ribadeneira

Contributed new reagents or analytic tools: Konstantinidis, Seu

Performed data analysis: Schroeder, Fulzele, Guichard, Kalfa, Seu, Konstantinidis, Fessler, Forsyth, Ribadeneira

Wrote or contributed to the writing of the manuscript: Schroeder, Fulzele, Forsyth, Ribadeneira, Guichard, Wilker, Marshall, Drake, Kalfa, Seu, Konstantinidis, Fessler

\section{Declaration of Interests}


PS, SG SF, and MDR are employees of Forma Therapeutics and may own shares in Forma Therapeutics.

KF is a previous employee of Forma Therapeutics and reports equity ownership.

AD is a previous employee of Forma Therapeutics and owns shares in Forma Therapeutics.

TAK receives research funding from Forma Therapeutics and from Agios Pharmaceuticals and honoraria from Agios Pharmaceuticals for participation in Steering Committee.

KGS, DK, GM, EW, and RF have nothing to declare. 


\section{References}

Agrawal RK, Patel RK, Shah V, Nainiwal L, and Trivedi B (2014) Hydroxyurea in sickle cell disease: drug review. Indian J Hematol Blood Transfus 30:91-96.

Ataga KI, Kutlar A, Kanter J, Liles D, Cancado R, Friedrisch J, Guthrie TH, Knight-Madden J, Alvarez OA, Gordeuk VR, Gualandro S, Colella MP, Smith WR, Rollins SA, Stocker JW, and Rother RP (2017) Crizanlizumab for the prevention of pain crises in sickle cell disease. N Engl J Med 376:429-439.

Banerjee T and Kuypers FA (2004) Reactive oxygen species and phosphatidylserine externalization in murine sickle red cells. Br J Haematol 124:391-402.

Betz T, Lenz M, Joanny JF, and Sykes C (2009) ATP-dependent mechanics of red blood cells. Proc Natl Acad Sci U S A 106:15320-15325.

Bianchi P, Fermo E, Glader B, Kanno H, Agarwal A, Barcellini W, Eber S, Hoyer JD, Kuter DJ, Maia TM, Mañu-Pereira MDM, Kalfa TA, Pissard S, Segovia JC, van Beers E, Gallagher PG, Rees DC, and van Wijk R (2019) Addressing the diagnostic gaps in pyruvate kinase deficiency: consensus recommendations on the diagnosis of pyruvate kinase deficiency. Am J Hematol 94:149-161.

Blair HA (2020a) Crizanlizumab: first approval. Drugs 80:79-84.

Blair HA (2020b) Voxelotor: first approval. Drugs 80:209-215.

Brandow AM and Panepinto JA (2010) Hydroxyurea use in sickle cell disease: the battle with low prescription rates, poor patient compliance and fears of toxicities. Expert Rev Hematol 3:255-260.

Castro O (1980) Viability and function of stored sickle erythrocytes. Transfusion 20:695-703. 
Charache S, Grisolia S, Fiedler AJ, and Hellegers AE (1970) Effect of 2,3-diphosphoglycerate on oxygen affinity of blood in sickle cell anemia. J Clin Invest 49:806-812.

Chubukov V, Johnson K, Kosinski P, Clasquin M, Jha A, Kim H, Roddy T, Merica E, Barbier A, Dang L, Silverman L, and Kung C (2016) Characterization of metabolic response to AG348 , an allosteric activator of red cell pyruvate kinase, in healthy volunteers and pyruvate kinase deficiency patients. Blood 128:2452.

Clark MR, Mohandas N, and Shohet SB (1980) Deformability of oxygenated irreversibly sickled cells. J Clin Invest 65:189-196.

da Guarda CC, Yahouédéhou S, Santiago RP, Neres J, Fernandes CFL, Aleluia MM, Figueiredo CVB, Fiuza LM, Carvalho SP, Oliveira RM, Fonseca CA, Ndidi US, Nascimento VML, Rocha LC, and Goncalves MS (2020) Sickle cell disease: a distinction of two most frequent genotypes (HbSS and HbSC). PLoS One 15:e0228399.

Dayneka NL, Garg V, and Jusko WJ (1993) Comparison of four basic models of indirect pharmacodynamic responses. J Pharmacokinet Biopharm 21: 457-478.

de Jong K, Larkin SK, Styles LA, Bookchin RM, and Kuypers FA (2001) Characterization of the phosphatidylserine-exposing subpopulation of sickle cells. Blood 98:860-867.

Eaton WA and Bunn HF (2017) Targeting sickle cell disease by targeting HbS polymerization. Blood 129:2719-2726.

Ericsson A, Green N, Gustafson G, Lancia DR. Jr, Marshall G, Mitchell L, Richard D, Wang Z, Forsyth S, Kelly PJ, Mondal M, Ribadeneira M, and Schroeder P (2020) Treating sickle cell disease with a pyruvate kinase R activating compound. United States Patent Number 10,675,274. Patent Images (uspto.gov). Accessed June 8, 2021.

Gallagher P (2017) Disorders of erythrocyte hydration. Blood 130:2699-2708. 
Grace RF, Layton DM, and Barcellini W (2019) How we manage patients with pyruvate kinase deficiency. Br J Haematol 184:721-734.

Guarnone R, Centenara E, and Barosi G (1995) Performance characteristics of Hemox-Analyzer for assessment of the hemoglobin dissociation curve. Haematologica 80:426-430.

Hebbel RP and Hedlund BO (2017) Sickle hemoglobin oxygen affinity-shifting strategies have unequal cerebrovascular risks. Am J Hematol 93:321-325.

Kato GJ, Piel FB, Reid CD, Gaston MH, Ohene-Frempong K, Krishnamurti L, Smith WR, Panepinto JA, Weatherall DJ, Costa FF, and Vichinsky EP (2018) Sickle cell disease. Nat Rev Dis Primers 4:18010.

Kha L, Cohen M, Chen Y, Kim H, Silver B, Agresta S, Merica E, Kung C, Kosinski P, Silverman L, Biller S, and Yang H (2015) Population pharmacokinetics and pharmacodynamics of AG-348 in healthy human volunteers guide dose selection for the treatment of pyruvate kinase deficiency. Blood 126:3336.

Koralkova P, van Solinge WW, and van Wijk R (2014) Rare hereditary red blood cell enzymopathies associated with hemolytic anemia - pathophysiology, clinical aspects, and laboratory diagnosis. Int J Lab Hematol 36:388-397.

Kung C, Hixon J, Kosinski PA, Cianchetta G, Histen G, Chen Y, Hill C, Gross S, Si Y, Johnson K, DeLaBarre B, Luo Z, Gu Z, Yao G, Tang H, Fang C, Xu Y, Lv X, Biller S, Su SM, Yang H, Popovici-Muller J, Salituro F, Silverman L, and Dang L (2017) AG-348 enhances pyruvate kinase activity in red blood cells from patients with pyruvate kinase deficiency. Blood 130:1347-1356. 
Lanzkron S, Carroll CP, and Haywood C, Jr. (2010) The burden of emergency department use for sickle-cell disease: an analysis of the national emergency department sample database. Am J Hematol 85:797-799.

Ma Q, Wyszynski DF, Farrell JJ, Kutlar A, Farrer LA, Baldwin CT, and Steinberg MH (2007) Fetal hemoglobin in sickle cell anemia: genetic determinants of response to hydroxyurea. Pharmacogenomics J 7:386-394.

MacDonald R (1977) Red cell 2,3-diphosphoglycerate and oxygen affinity. Anaesthesia 32:544553.

McMahon TJ (2019) Red blood cell deformability, vasoactive mediators, and adhesion. Front Physiol 10:1417.

National Research Council (US) Committee for the Update of the Guide for the Care and Use of Laboratory Animals. (2011). Guide for the Care and Use of Laboratory Animals, 8th edition. National Academies Press, Washington, D.C.

Novelli EM and Gladwin MT (2016) Crises in sickle cell disease. Chest 149:1082-1093.

Ortiz OE, Lew VL, and Bookchin RM (1990) Deoxygenation permeabilizes sickle cell anaemia red cells to magnesium and reverses its gradient in the dense cells. $J$ Physiol 427:211226.

Ould Amar AK, Kerob-Bauchet B, Robert P, Leconte C, Maier H, Bera O, Plumelle Y, Hyronimus JC, and Césaire R (1996) Assessment of qualitative functional parameters of stored red blood cells from donors with sickle cell trait (AS) or with heterozygote (AC) status. Transfus Clin Biol 3:225-233.

Poillon WN, Kim BC, Labotka RJ, Hicks CU, and Kark JA (1995) Antisickling effects of 2,3diphosphoglycerate depletion. Blood 85:3289-3296. 
Rab MAE, van Oirschot BA, Bos J, Merkx TH, van Wesel ACW, Abdulmalik O, Safo MK, Versluijs BA, Houwing ME, Cnossen MH, Riedl J, Schutgens REG, Pasterkamp G, Bartels M, van Beers EJ, and van Wijk R (2019) Rapid and reproducible characterization of sickling during automated deoxygenation in sickle cell disease patients. Am J Hematol 94:575-584.

Raftos JE, Lew VL, and Flatman PW. Refinement and evaluation of a model of Mg2+ buffering in human red cells (1999) Eur J Biochem 263:635-645.

Rivera A, Ferreira A, Bertoni D, Romero JR, and Brugnara C (2005) Abnormal regulation of Mg2+ transport via Na/Mg exchanger in sickle erythrocytes. Blood 105:382-386.

Sadaf A, Seu KG, Thaman E, Fessler R, Konstantinidis DG, Bonar HA, Korpik J, Ware RE, McGann PT, Quinn CT, and Kalfa TA. (2021) Automated Oxygen Gradient Ektacytometry: A Novel Biomarker in Sickle Cell Anemia. Front Physiol 12:636609.

Shah N, Bhor M, Xie L, Halloway R, Arcona S, Paulose J, and Yuce H (2019) Treatment patterns and economic burden of sickle-cell disease patients prescribed hydroxyurea: a retrospective claims-based study. Health Qual Life Outcomes 17:155.

Sharma A, and Jusko WJ (1998) Characteristics of indirect pharmacodynamic models and applications to clinical drug responses. Br J Clin Pharmacol 45:229-239.

Shrestha A, Chi M, Wagner K, Malik A, Korpik J, Drake A, Fulzele K, Guichard S, and Malik P (2021) FT-4202, an oral PKR activator, has potent antisickling effects and improves RBC survival and Hb levels in SCA mice. Blood Adv 5: 2385-2390.

Soupene E and Kuypers FA. Identification of an erythroid ATP-dependent aminophospholipid transporter (2006) Br J Haematol 133:436-438. 
Steinberg MH, Lu ZH, Barton FB, Terrin ML, Charache S, and Dover GJ (1997) Fetal hemoglobin in sickle cell anemia: determinants of response to hydroxyurea. Multicenter Study of Hydroxyurea. Blood 89:1078-1088.

Steinberg MH (2008) Sickle cell anemia, the first molecular disease: overview of molecular etiology, pathophysiology, and therapeutic approaches. ScientificWorldJournal 8:12951324.

Sundd P, Gladwin MT, and Novelli EM (2019) Pathophysiology of sickle cell disease. Annu Rev Pathol 14:263-292.

Telen MJ (2007) Role of adhesion molecules and vascular endothelium in the pathogenesis of sickle cell disease. Hematology Am Soc Hematol Educ Program:84-90.

Vichinsky E, Hoppe CC, Ataga KI, Ware RE, Nduba V, El-Beshlawy A, Hassab H, Achebe MM, Alkindi S, Brown RC, Diuguid DL, Telfer P, Tsitsikas DA, Elghandour A, Gordeuk VR, Kanter J, Abboud MR, Lehrer-Graiwer J, Tonda M, Intondi A, Tong B, Howard J, and Investigators HT (2019) A phase 3 randomized trial of voxelotor in sickle cell disease. N Engl J Med 381:509-519.

Weed RI, LaCelle PL, and Merrill EW (1969) Metabolic dependence of red cell deformability. J Clin Invest 48:795-809.

Weiss E, Cytlak UM, Rees DC, Osei A, and Gibson JS (2012) Deoxygenation-induced and $\mathrm{Ca}(2+)$ dependent phosphatidylserine externalisation in red blood cells from normal individuals and sickle cell patients. Cell Calcium 51:51-56.

Yang H, Merica E, Chen Y, Cohen M, Goldwater R, Kosinski PA, Kung C, Yuan ZJ, Silverman L, Goldwasser M, Silver BA, Agresta S, and Barbier AJ (2019) Phase 1 single- and multiple-ascending-dose randomized studies of the safety, pharmacokinetics, and 
pharmacodynamics of AG-348, a first-in-class allosteric activator of pyruvate kinase R, in healthy volunteers. Clin Pharmacol Drug Dev 8:246-259.

Yusuf HR, Atrash HK, Grosse SD, Parker CS, and Grant AM (2010) Emergency department visits made by patients with sickle cell disease: a descriptive study, 1999-2007. Am J Prev Med 38:S536-S541.

Zanella A, Fermo E, Bianchi P, and Valentini G (2005) Red cell pyruvate kinase deficiency: molecular and clinical aspects. Br J Haematol 130:11-25. 


\section{Unnumbered Footnotes}

This study was funded by Forma Therapeutics, Inc., Watertown, MA.

Pharmacokinetic data from healthy subjects following a single dose of etavopivat was previously presented at the European Hematology Association Annual Congress, 2020 (Estepp JH et al, Hemasphere, 2020, 4, 709-710).

Reprint requests to:

Theodosia A. Kalfa,

Address: Cincinnati Children’s Hospital Medical Center, Cincinnati, Ohio

Tel: 513-636-0989

Fax: 513-636-1330

E mail: Theodosia.Kalfa@cchmc.org

\section{Numbered Footnotes}

${ }^{1}$ Co first authors

${ }^{2}$ At the time of study conduct 


\section{[[Figure Legends]]}

Fig. 1. Relationship between the PK of etavopivat and the PD of 2,3-DPG in non-human primates. PK profiles of NHP $(n=4)$ administered a single $50-\mathrm{mg} / \mathrm{kg}$ dose of etavopivat demonstrated rapid absorption and mean $\mathrm{C}_{\max }$ of $1823 \mathrm{ng} / \mathrm{ml}$ etavopivat and an $\mathrm{AUC}_{0-24}$ of 8877 $\mathrm{ng} / \mathrm{mL}^{*} \mathrm{~h}\left(\mathrm{AUC}_{0-\mathrm{inf}}=9007 \mathrm{ng} / \mathrm{mL}^{*} \mathrm{~h}\right)$. At this dose level, 2,3-DPG decreased by an average of $47 \%$ between 12 and $24 \mathrm{~h}$ post dose versus baseline (paired T-test; $P=0.04$ ). Data are expressed as mean \pm S.D.

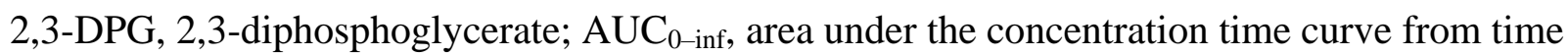
0-infinity; $\mathrm{C}_{\max }$; maximum plasma concentration; NHP, non-human primate; PD, pharmacodynamics; PK, pharmacokinetics; S.D., standard deviation.

Fig. 2. Dose-response time course modulation of 2,3-DPG and ATP following 5 consecutive days of QD dosing of etavopivat in non-human primates. $N=4$ per treatment group. For all graphs, data are expressed as mean \pm S.D. and analyzed using paired T-tests (2,3-DPG, baseline vs $12 \mathrm{~h}$ post last dose on Day 5; ATP, Day 1 vs Day 5). (Panel A) Blood 2,3-DPG profile on day 1 and day 5 of consecutive QD dosing of 3, 8, or $22 \mathrm{mg} / \mathrm{kg}$. (Panel B) Plasma PK profile of etavopivat on day 1 and day 5 of consecutive QD dosing of 3, 8, or $22 \mathrm{mg} / \mathrm{kg}$. (Panel C) Blood ATP profile on day 1 and day 5 of consecutive QD dosing of 3, 8, or $22 \mathrm{mg} / \mathrm{kg}$.

2,3-DPG, 2,3-diphosphoglycerate; ATP, adenosine triphosphate; PK, pharmacokinetic; QD, once daily; S.D., standard deviation.

Fig. 3. Day 5 percent changes in 2,3-DPG and ATP, along with exposure (Day $5 \mathrm{AUC}_{0-24}$ ) following 5 consecutive days of QD dosing of etavopivat in non-human primates. $N=4$ per 
etavopivat treatment group and $N=3$ for the placebo group. Data plotted are mean \pm S.D, analyzed using paired T-tests. ${ }^{*} P<0.05$; $* * P<0.01$; $* * * P<0.001$. Day $5 \mathrm{AUC}_{0-24}$ data are mean (S.D.).

2,3-DPG, 2,3-diphosphoglycerate; ATP, adenosine triphosphate; $\mathrm{AUC}_{0-24}$, area under the concentration time curve from time 0-24 hours after dosing QD, once daily; S.D., standard deviation.

Fig. 4. Etavopivat improves the Hb-oxygen dissociation curve in healthy subjects and in $\mathrm{RBC}$ from sickle cell donors with HbSS and HbSC disease. Treatment with etavopivat significantly decreased the $\mathrm{P}_{50}$ of healthy subjects treated with a single dose of etavopivat $(n=6)$ (Panel A). Isolated RBC from $\mathrm{HbSS}$ or HbSC donors were treated ex vivo with either $20 \mu \mathrm{M}$ etavopivat or DMSO (vehicle) for 4 hours at $37^{\circ} \mathrm{C}$. Treatment with etavopivat significantly decreased the $\mathrm{P}_{50}$ in RBCs from both HbSS ( $n=13$; Panel B) and $\operatorname{HbSC}(n=6$; Panel C) donors. Representative oxygen equilibrium curves are shown for HbSS (Panel D) and HbSC (Panel E). Data were analyzed using non-parametric Wilcoxon matched-pairs signed rank test. $* P<0.05 ; * * * P<0.001$. Hb, hemoglobin; HbSC, hemoglobin SC; HbSS, hemoglobin SS; HS, healthy subjects; $\mathrm{P}_{50}$, the dissolved oxygen pressure at which $\mathrm{Hb}$-oxygen-binding is $50 \%$ saturated; RBC, red blood cells; SAD, single-ascending dose; SCD, sickle cell disease.

Fig. 5. Etavopivat reduced the dissolved oxygen pressure at which HbSS or HbSC RBC initiate sickling. Isolated RBC from donors with either $\mathrm{HbSS}$ or HbSC genotype were treated ex vivo with either $20 \mu \mathrm{M}$ etavopivat or DMSO (vehicle) for 4 hours at $37^{\circ} \mathrm{C}$. Curves for $\mathrm{RBC}$ deformability as a function of dissolved oxygen pressure (oxygenscan) were constructed using 
Lorrca $^{\circledR}$. The PoS at which the deformation of RBC reached 5\% from baseline was calculated and plotted. Treatment with etavopivat significantly decreased the PoS in RBCs from both HbSS ( $n=11$; Panel A) and $\operatorname{HbSC}(n=6$; Panel B) donors. Representative oxygenscans for RBCs from a HbSS donor (Panel C) and a HbSC donor (Panel D) are shown. Data were analyzed using the non-parametric Wilcoxon matched-pairs signed rank test. $* P<0.05$.

DMSO, dimethyl sulfoxide; HbSC, hemoglobin SC; HbSS, hemoglobin SS; PoS, point of sickling; RBC, red blood cells; SCD, sickle cell disease.

Fig. 6. Relationship between the PK of etavopivat and the PD of 2,3-DPG in healthy human subjects. PK profiles in healthy subjects $(n=6)$ administered $700 \mathrm{mg}$ of etavopivat demonstrated rapid absorption and mean $\mathrm{C}_{\max }$ of $2204 \mathrm{ng} / \mathrm{ml}$ and $\mathrm{AUC}_{0 \text {-inf }}$ of $6995 \mathrm{ng} \cdot \mathrm{h} / \mathrm{ml}$. PD analysis of 2,3DPG in the same subjects demonstrated maximum reductions at 24 hours with durable reductions of 2,3-DPG of $48 \%$ through 48 hours and a return to baseline by day 7 (Panel A). Panel B is presented to show greater clarity at early timepoints (0-24 hours). Data are mean \pm S.D. at each time point.

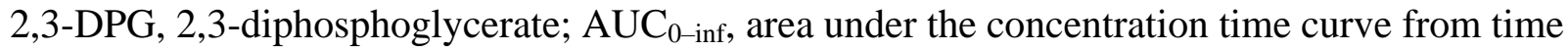
0-infinity; $\mathrm{C}_{\max }$; maximum plasma concentration; $\mathrm{PD}$, pharmacodynamic; $\mathrm{PK}$, pharmacokinetic; S.D., standard deviation.

Fig. 7. Relationship between 2,3-DPG and $\mathrm{P}_{50}$ in healthy subjects following a single 700-mg dose of etavopivat. Hb-oxygen affinity shifts were measured in the blood of healthy subjects ( $n$ =6) prior to dosing etavopivat and at 24 hours post-dose, coinciding with an increased $\mathrm{Hb}-$ 
oxygen affinity (a decrease in $\mathrm{P}_{50}$ ) that was positively correlated with decreases in the mean blood concentrations of 2,3-DPG.

2,3-DPG, 2,3-diphosphoglycerate; $\mathrm{Hb}$, hemoglobin; $\mathrm{P}_{50}$, the partial pressure of dissolved oxygen at which $\mathrm{Hb}$ is $50 \%$ saturated with oxygen. 


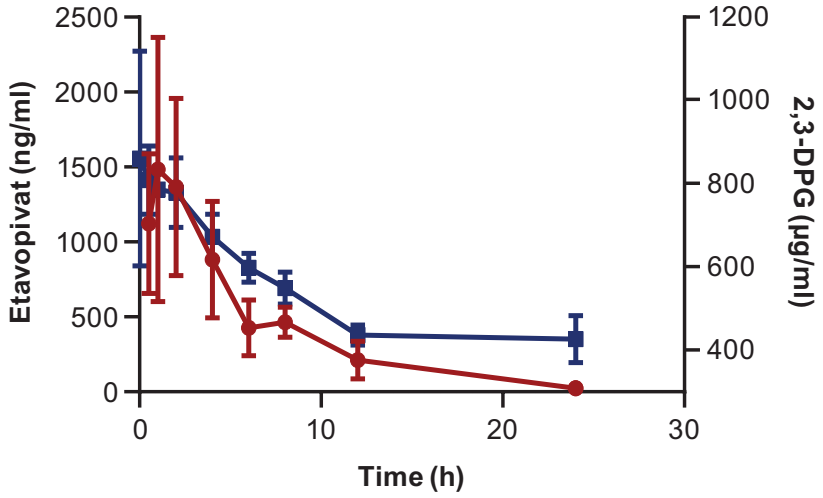

$\rightarrow$ Etavopivat $\rightarrow$ 2,3-DPG

Figure 1 


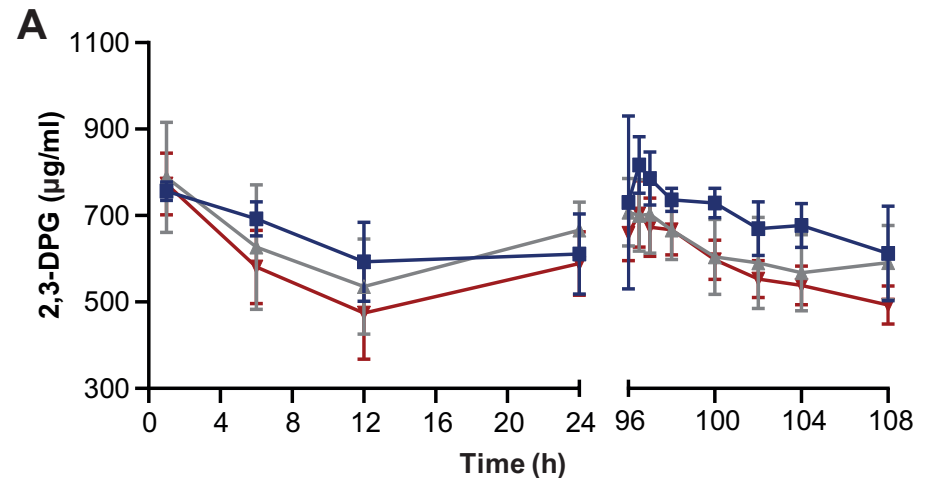

$-3 \mathrm{mg} / \mathrm{kg} \leftarrow 8 \mathrm{mg} / \mathrm{kg} \rightarrow 22 \mathrm{mg} / \mathrm{kg}$

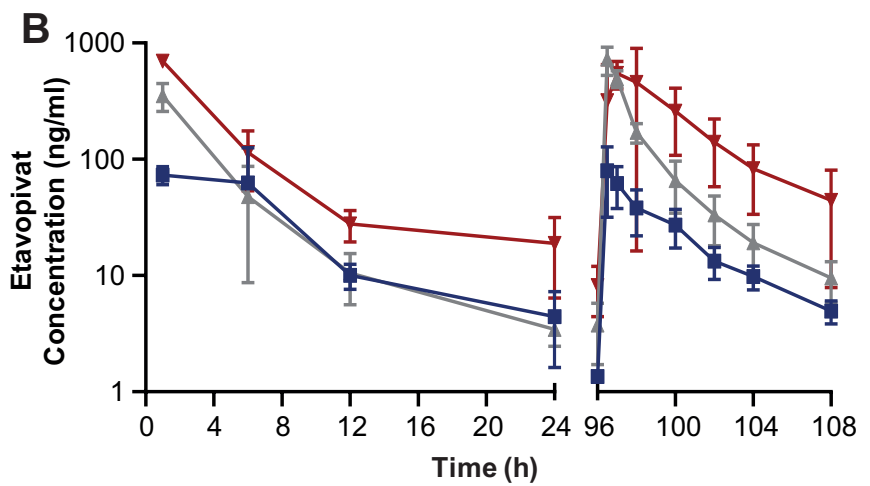

$\rightarrow 3 \mathrm{mg} / \mathrm{kg} \rightarrow 8 \mathrm{mg} / \mathrm{kg} \rightarrow 22 \mathrm{mg} / \mathrm{kg}$

C

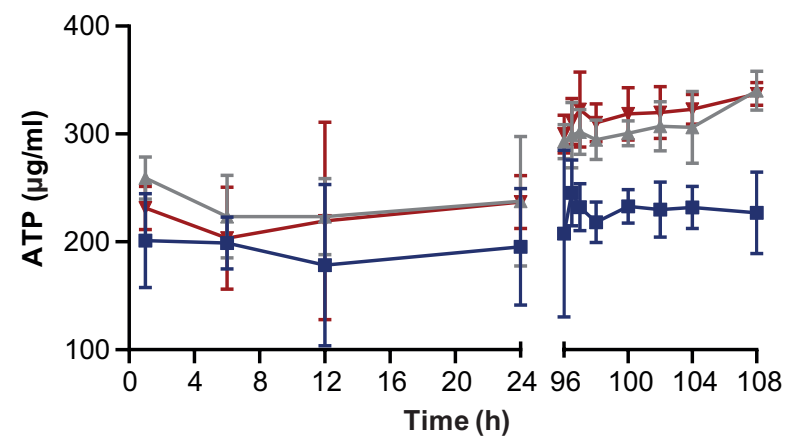

$\rightarrow 3 \mathrm{mg} / \mathrm{kg} \neq 8 \mathrm{mg} / \mathrm{kg} \leftarrow 22 \mathrm{mg} / \mathrm{kg}$ 


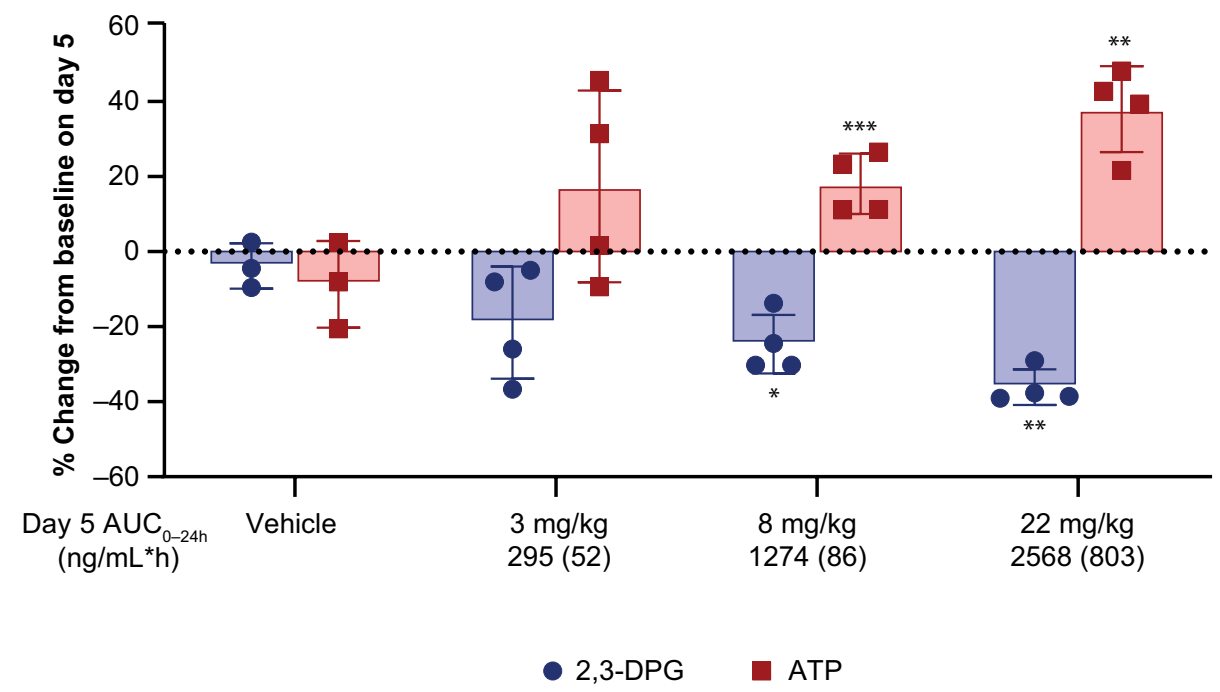


A

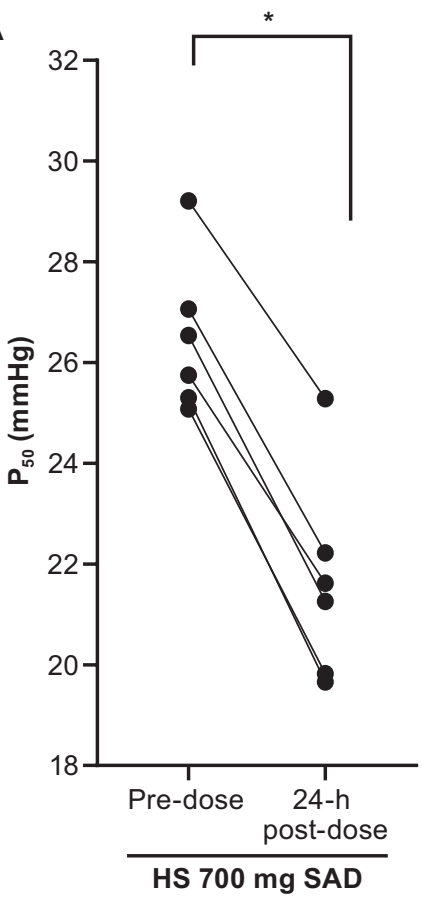

B

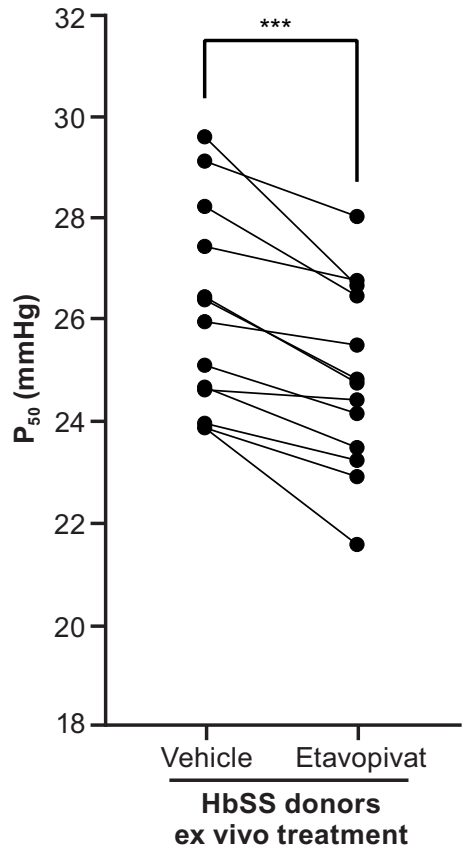

C

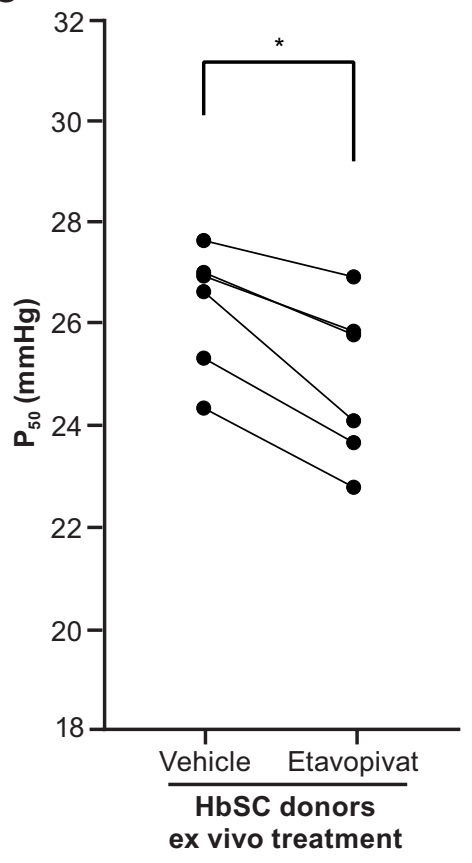

D

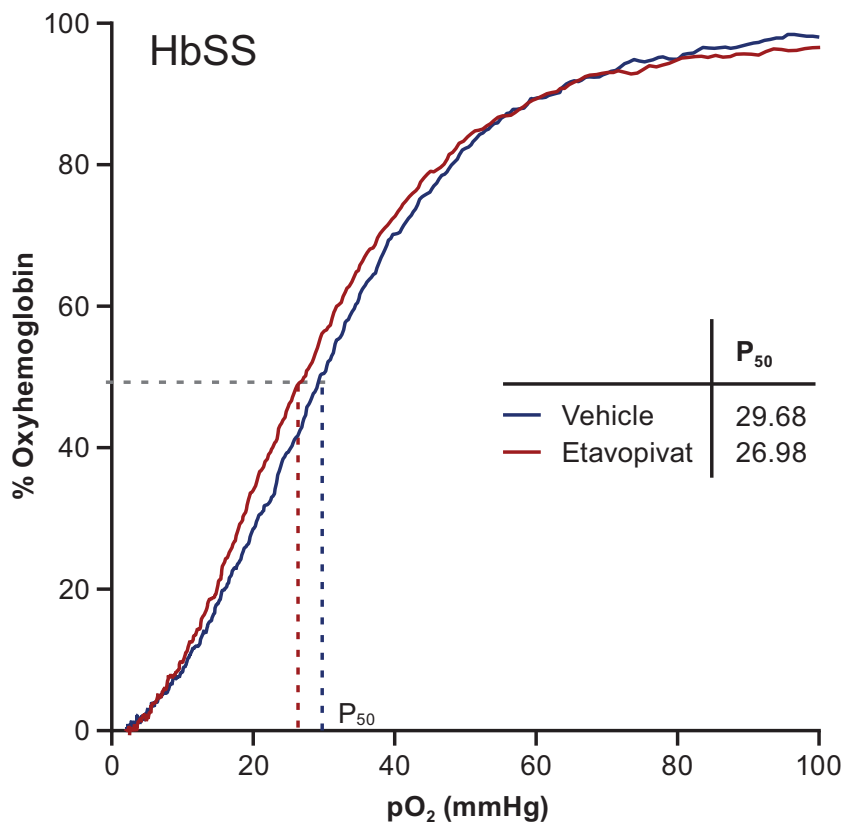

E

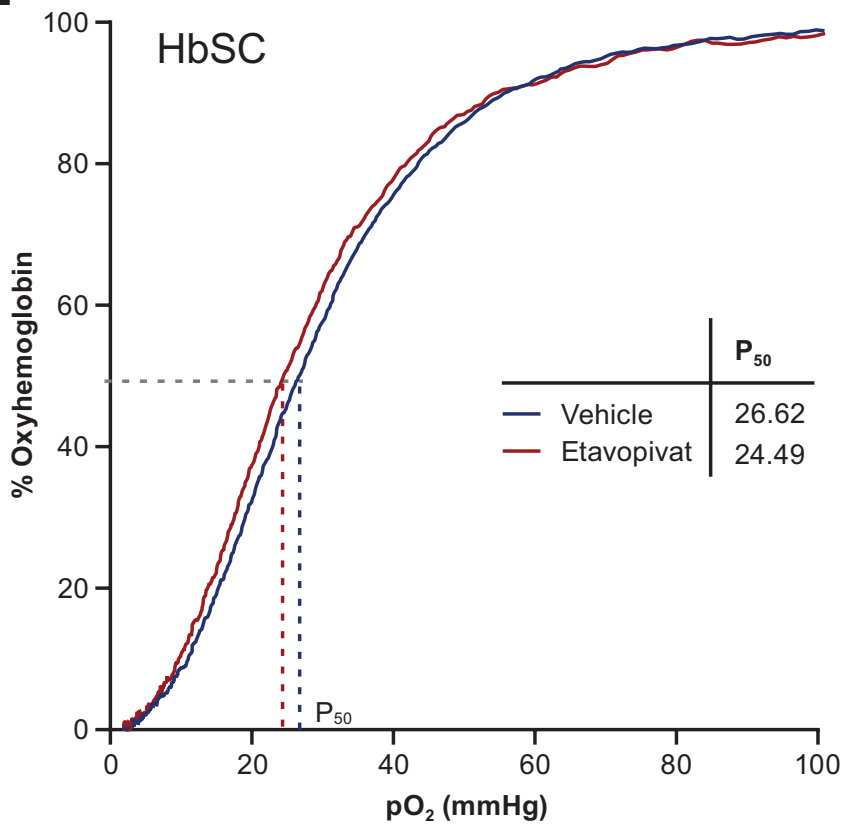



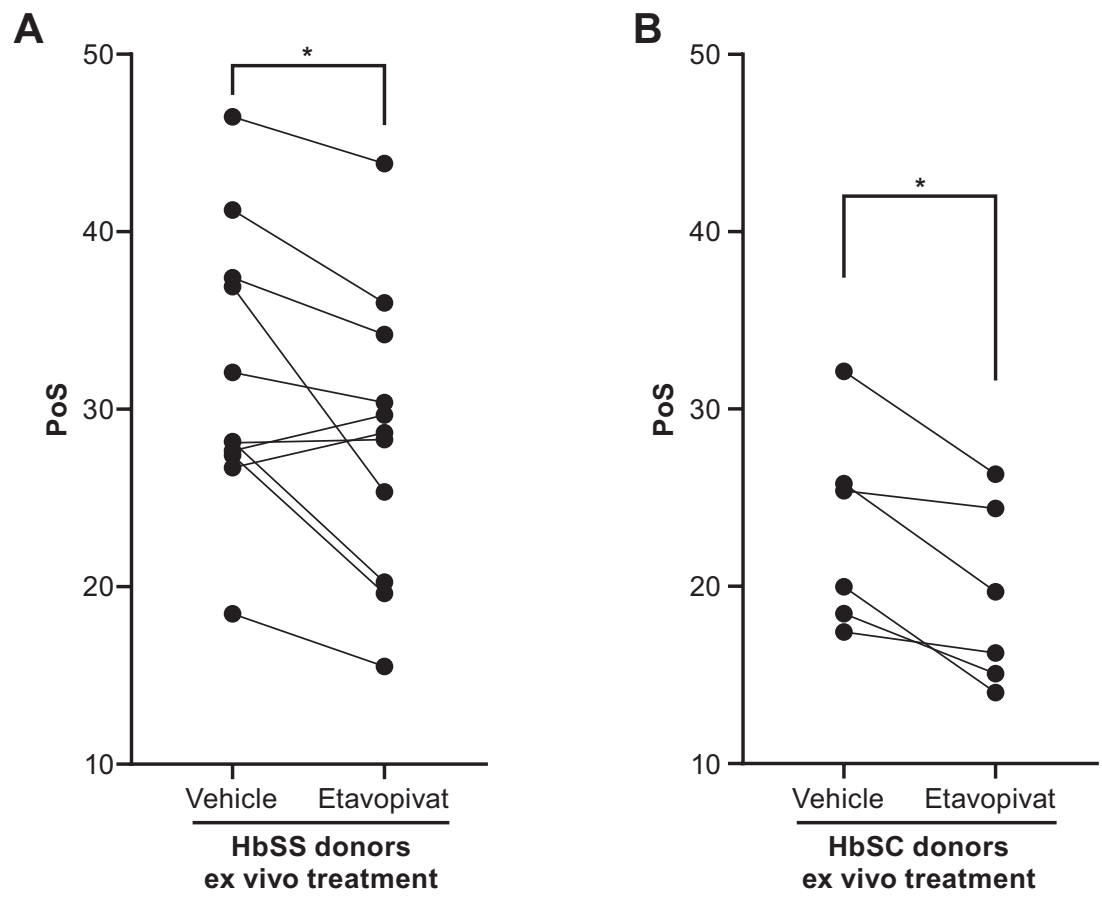

C

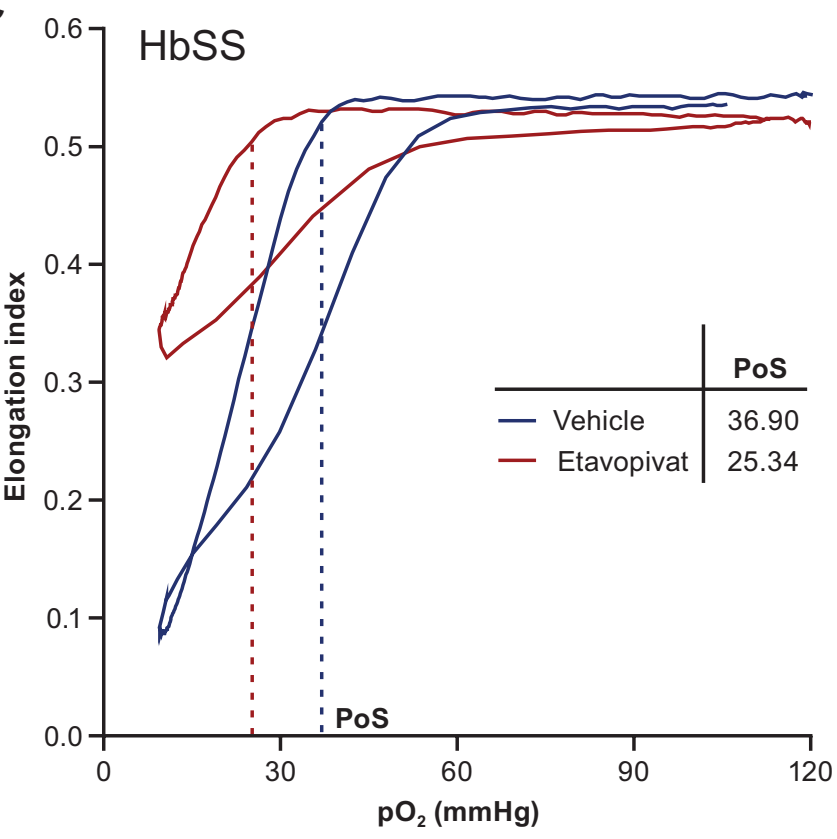

D

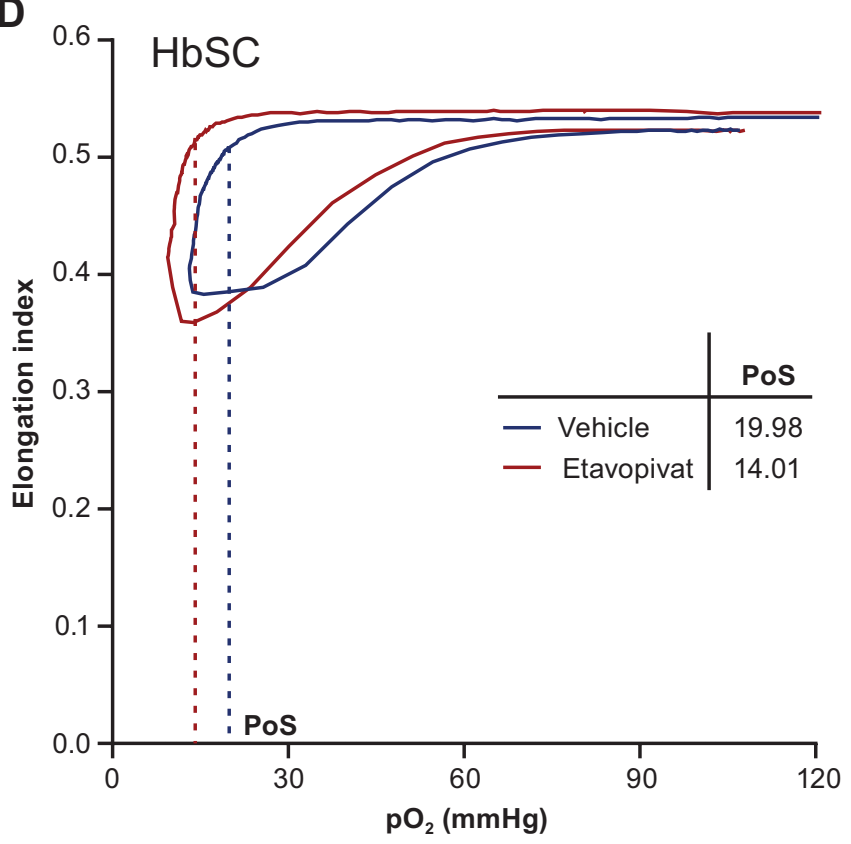




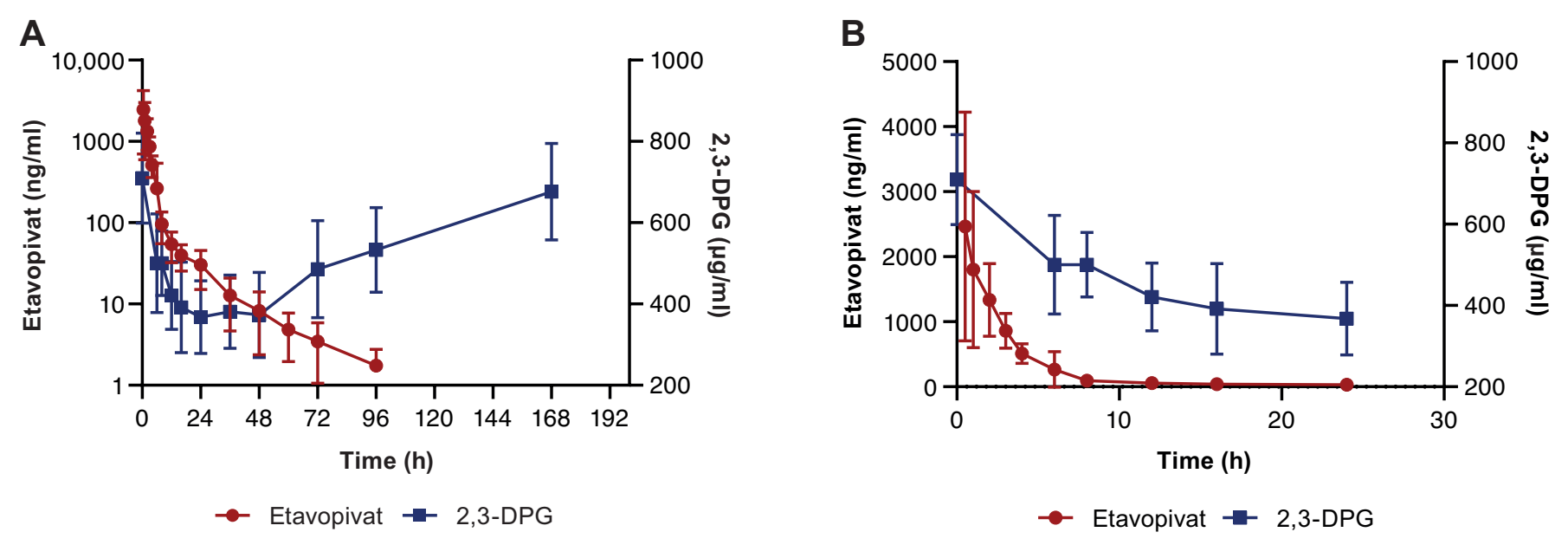




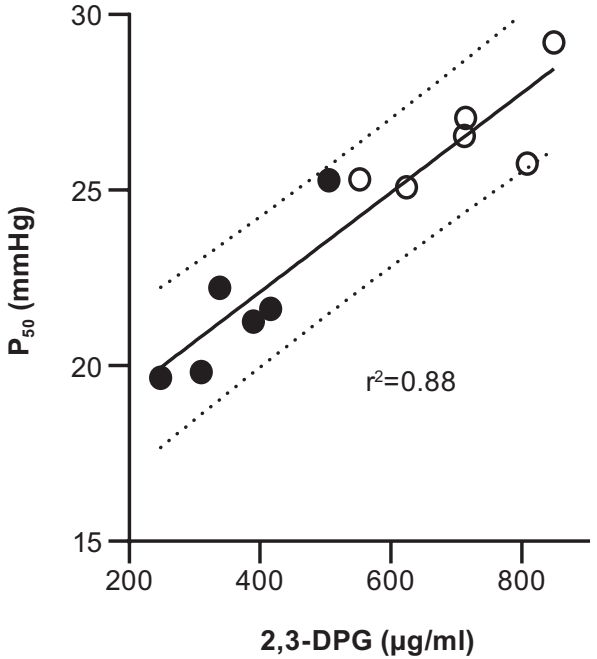

24-h post-dose $\mathrm{O}$ Pre-dose

Figure 7 